\title{
Using the Product Life Cycle as a Basis for a Product-Service Strategy Model
}

\author{
David Walters and Jyotirmoyee Bhattacharjya \\ Institute of Transport and Logistics Studies, The University of Sydney, Sydney, \\ NSW 2006, Australia \\ \{david.walters, jyotirmoyee.bhattacharjya\} @sydney.edu.au
}

\begin{abstract}
The recent financial problems of the 2008/10 GFC and the likelihood of similar events occurring in 2012/13 has 'spooked' business and consumer confidence and has resulted in fierce competition in both $\mathrm{B} 2 \mathrm{C}$ and in the derived demand companies in $\mathrm{B} 2 \mathrm{~B}$ markets. The problems are exacerbated by the very slow recovery response of developed economy business organizations, many facing competition from Asian companies whose business models have become sophisticated and are moving rapidly away from their traditional "high volume/low value" manufacturing expertise towards a "low volume/high value" value proposition thereby threatening well established traditional western companies; some are moving away from tangible/hardware products towards becoming solution providers.
\end{abstract}

Keywords: Innovation, Imitation, Commoditization, Value migration, the PRODUCT-service life cycle, the product-SERVICE life cycle.

\section{Introduction}

Today the engine for growth is Asia and the model has shifted from a business owing all of the production assets to managing partners in supply chains to even more complex relationships. While the focus on Asia by western organizations was originally about lowering costs in the supply chain; as these resource markets expanded they have become massive consumer markets in their own rights such that now China is the world's fastest growing market. More recently the Indian automotive market has been expanding rapidly. This has been accompanied by market led product and manufacturing process designs that call into question whether the "global products and platforms" that many manufacturers have strived for are really just extensions of Western requirements. The launch of the Nano (small automobile) by Tata, for example, identified a need for product and service design to reflect local requirements and capabilities. General Electric and Panasonic have introduced 'reverse/frugal' innovation into Asian markets based upon a policy that reflects "meeting local needs with local resources". It follows that the competitive strategy of western/traditional business models needs to be adapted to changing market circumstances. 


\section{Asian Innovation and Competition: An Issue for the $21^{\text {st }}$ Century}

There is no shortage of examples demonstrating the innovative ideas emerging from Asia. Much of this success is based upon open innovation, the use of external sources to enhance a company's internal research processes. These external sources may be other individuals in the same industry, not technically related to the company, professionals, entrepreneurs, or even ordinary consumers (crowd sourcing) that have a mind for innovation. Open innovation accepts the fact that knowledge is everywhere; companies benefit from the influx of externally sourced knowledge, and this ensures they keep from stagnating in their internal research and development. Many of the most important innovations consist of incremental improvements to products and processes aimed at the middle or the bottom of the income pyramid "Frugal" or "constraint-based" innovation takes the needs of poor consumers as a starting point and working backwards stripping the products down to their bare essentials. India's Mahindra \& Mahindra sells lots of small tractors to American hobby farmers, filling John Deere with fear. China's Haier has undercut Western competitors in a wide range of products, from air conditioners and washing machines to wine coolers. Godrej \& Boyce Manufacturing has developed a battery powered $\$ 70$ fridge. Li \& Fung (HK) and Chingquing Lifan Group (China) can use their huge supply chains to produce fashion items or motorcycles in response to demand. Aravind Eye Care System that makes high-quality eye care accessible to low income customers. Its founder, Dr. G. Venkataswamy, is applying the principles of McDonald's that led him to creative ideas about efficient, high-quality care that have had untold impact on the lives of hundreds of thousands of the poor of South India

Western organizations are responding to the imitation and reverse/frugal innovation that are becoming dominant forms of competition. GE and Smith \& Nephew's emerging market strategies, for example, also include mechanisms for deploying "reverse innovation" back to mature Western markets to widen the impact of its investments. In this way, the work they do within emerging markets benefits their key developed markets as well. There are powerful messages here for western based organizations. Thus it follows that if the western business model is to survive there are a few strategic considerations to be considered. One is to follow the merger and acquisition and strategic alliance route that companies such as GE, Pfizer, Abbot Laboratories, $A B B$ and others are pursuing. Another is to study market development trends very closely and watch and time the strategies being implemented by the "new competition"; these being, imitation, commoditization, and reverse innovation. We suggest the product-life cycle model offers a useful starting place.

\section{Revisiting the Product Life Cycle}

It is not only the shift towards the more intangible aspects of value delivery that are undergoing change; so too is the notion of the product life cycle (PLC); a concept that continues to appear in marketing texts (and sadly in boardroom thinking despite the 
fact that the original concept, in many instances, is older than many of the directors!). The PLC concept has been influenced by developments in the management of knowledge, technology, processes and relationships management. In the context of this discussion academic and corporate analysis should consider the planned transformation of the "product" delivered benefits into "service" benefits. This process is influenced by changing, or evolving customer expectations, and the improved business model delivery of competitors. This suggests a fresh look at the concept will be useful to this discussion.

Kotler [1] suggested the value of the product life cycle is "... that it provides insights into a product's competitive dynamics. At the same time the concept can prove misleading if not carefully used". He suggested further: "The product life cycle portrays distinct stages in the sales history of a product, corresponding to these stages are distinct opportunities and problems with respect to marketing strategy and profit potential. By identifying the stage that a product is in, or may be headed toward, companies can formulate better marketing plans". Kotler's words of caution were reinforced by comments concerning the level of aggregation used to apply the life cycle theory. He used an illustration based on the work of Page (unpublished) which suggested three levels of analysis. Page produced evidence to suggest that we should consider product category, product form and brand, and used alcohol beverages as an example. Page's case example suggested that over time, depending on which level the analysis is conducted, the 'stage' of the product life cycle might differ from the life cycle stages at other levels. Furthermore, as Kotler ably demonstrated, there are many shapes that product life cycles may adopt. This raises an issue concerning the reliability of the PLC for planning purposes.

It has been argued that the product life cycle was not as reliable a model as might have been hoped for, particularly if large investment is required. Doyle [2] proposed that if there is no predictable life cycle and similarly no standard pattern of market evolution, alternatives are required. He suggested there are common processes that shape markets and consequently that by analyzing these managers can anticipate new markets and how competition will develop, and in so doing determine the likely shape of market volumes. This "... can develop strategies both to capitalize on these changes and to influence those forces of change". The forces-or common processes-he identified are customers, competition, new entrants, substitute products and technologies, and supply relationships; in the fifteen years that have passed these effects have become increasingly dynamic and often unpredictable.

Prior to this, Ansoff [3] had revised the product-life-cycle model, offering a more realistic and current view. Ansoff argued that demand life cycle for a product-service is ongoing - in other words end-user 'product application needs' (the desired value) remain unchanged - we continue to 'count and calculate', and undertake many other activities; what has changed is the ways and means of achieving the outcomes. Technological development has accelerated and introduces the notion of the DTLC (demand technology life cycles). We suggest technological development is not the only influence; knowledge management, relationship management, and process management have had influence to a greater or lesser degree. The scope of a business may be defined as being a combination of customer needs, functions, customer 
groups/segments and technologies in a viable market cell within which the business can focus its capabilities and capacities to service customer needs and segments within the current technology base. Ansoff identified space created within the demand technology cycle as a strategic business area (SBA) and utilizes this idea for strategic market planning decisions.

If the demand technology cycle provides the strategic business area within which the firm is to apply its capabilities and capacities; then applications cycles create operational business areas. It is within these that a range of product applications appear using the technology of the demand technology cycle. Thus each strategic business area potentially offers a number of product application technology opportunities within which organizational product life cycles, individual product-service offers, describe the product variants possible within the available technology and are offered by competing organizations. Examples can be seen in the computer industry with competing notebook products, tablets and ultra-thin note books, each representing competitive activity in an applications cycle. Within this cycle manufacturers' individual brands are offered. The approach is essentially customer/market led and linked with research and development activities which identify emerging customer needs and technological feasibility.

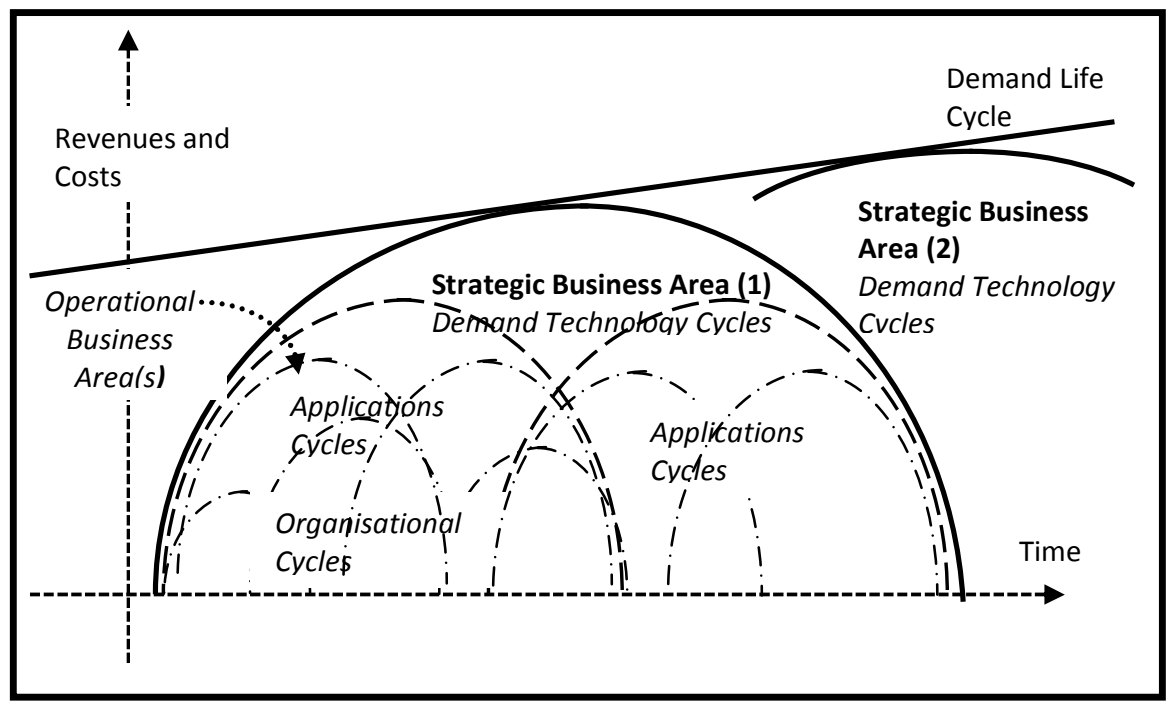

Fig. 1. A revised approach to the product life cycle

Figure one depicts ongoing demand life cycle as a growth trend (simplified to be a straight line) and servicing the demand are a series of demand technology cycles (within which two applications cycles can be observed). It is within the organization lifecycles that individual companies (and network structures) compete. At a macro level the strategic planning cycles (within strategic business areas) are selective competitive responses to meet imitation, commoditization, and value migration with 
strategies based upon reverse innovation, asset management, and, solution provision. At a micro level operational planning (within applications cycles) product-service variations are based upon the technology prescribed by the application (for example in computer hardware we currently have a cluster of 'tablet' products); within the applications cycles organizational cycles appear offering specific brand based value propositions. See Fig. 1.

\section{Product-Service Life Cycle Strategy}

Johnson [4] describes how Hilti (a leading hand-power tool manufacturer) realized that its value proposition with its emphasis on being a premium brand had lost its visibility with major customers. The product became "commoditized"; users began to regard it as disposable and after-use care was ignored. This suggests a transformation of the product life cycle model one that reflects what appears to be a move towards a business model that has emphasis on "asset management and cash flow performance"; suggesting a "PRODUCT-service" as being a predominantly tangible product providing "hardware" solutions to a customer problem and is clearly applicable to both business-to-business and business-to-consumer market sectors and as competition intensifies the service content of the package can become a critical factor in vendor/customer relationships and at a particular time (or situation) in the relationship the PRODUCT-service becomes a product-SERVICE. The 'solutions' response approach by organizations such as IBM, Rolls Royce Engines, and Boeing) is to deliver "value-based" service products. IBM's recently announced financial results suggest their 'solutions' business model is considerably more successful than the tangible product computer hardware business model. We suggest in this paper that the somewhat neglected product-life-cycle model can provide a structured approach to the construction of a workable business model by focusing on strategic pathways over time.

Recent Capgemini [5] research demonstrates the increasing importance of integrating service into product strategy 'packages'. It adds emphasis to the notion of the PRODUCT-service/product-SERVICE concept whereby as customer attitudes shift the PRODUCT-service 'package' moves through a life cycle and emphasis is placed upon product-SERVICE. Capgemini's research suggests that post-2000 a number of issues became important in the vendor-customer equation. These include; increasing costs, reduced margins (for both vendor and customer), rapid commoditization (particularly noticeable in computer hardware), and changing customer expectations. See also Capgemini [6] for a review of companies' approaches to creating competitive advantage by planning their product-SERVICE strategies.

Successful businesses plan response strategies that manage the migration of their PRODUCT-Service value proposition towards one based upon a product-SERVICE offer. Katz [7] suggests this may explain the problems currently being experienced by the Japanese electronics industry; rather than compete with Samsung (and others) all having the advantage of low cost capital and superior (and more efficient) 
manufacturing processes. An immediate response was to look for synergy and economies of scales from mergers. Elpida, a manufacturer of DRAM chips, was one such attempt by merging the relevant activities of Hitachi, NEC, and Mitsubishi. Elpida filed for bankruptcy in February 2012. See figure two.



Fig. 2. Plotting competitive strategy in a revised product-service life cycle

A "PRODUCT-service" is a predominantly tangible product that provides a "hardware" solution to a customer problem and is clearly applicable to both B2B and B2C market sectors. As competition intensifies the service content of the package can become a critical factor in vendor/customer relationships and at a particular time (as for Hilti) in the relationship the PRODUCT-service may become a productSERVICE to maintain competitive advantage.

Maintaining customer performance management is vital; it is indisputable that the growth rates in the emerging markets exceeds that of the older, traditional markets, so much so that a number of large, global, capital equipment manufacturers are locating their production facilities in these markets; this is not simply for operational outsourcing benefits but is more a strategic outsourcing move to create strategic alliances in the emerging market to ensure 'market viability and longevity' by establishing a business model that offers a locally produced relevant, 'fit for purpose' product-service value propositions to local end-user customers at competitive prices. The "reverse innovation" or "frugal innovation" activities of $\boldsymbol{G} \boldsymbol{E}$ and Panasonic to reengineer their product-services to meet specific 'local' requirements (affordable healthcare and a comfortable living environment) are reflecting "a service-dominant view in which intangibility, exchange processes, and relationships are central". [8]

The model presented in figure two is being used by a number of Innovator organizations as response to the territorial expansion from Asian organizations. 
Examples of organizations using a PRODUCT-service/product-SERVICE strategy successfully include: Asset Management; Boeing is offering users a global routine service facility; working with its airline customers it can position parts inventories in locations where aircraft service requirements become due, this may relieve the customer of planning both flight and servicing schedules so that they coincide. Caterpillar, Rolls Royce Engines provide early indication of impending product failure enabling service personnel to put into motion product component replacement responses as a failure occurs. Solution Provider strategies are being pursued by IBM, Dell, and Cisco; IBM and Cisco accumulate knowledge and refine their skills through their research activities and their experiential learning as they help clients implement innovations. Working with multiple clients creates learning effect economies and provides opportunity to engage in repeated application of skills, which helps them address problems and enhance their ability to recognize cause-and-effect relationships. Value migration occurs as both economic and shareholder value flows away from obsolescent (and obsolete) business models. Slywotzky [9] argued that new models offer the same benefits to customers but at lower cost by changing the model structure. This change often results in a restructuring of profit sharing throughout the business model. An example of value migration as a response to customer expectations that have changed is Dell's adjustment to its business model and its value proposition; Dell now focuses on what it calls a "segmented supply chain," offering solutions to various groups of customers depending as much on what they need as what they're willing to pay for. Reverse/frugal innovation is being practiced by a number of global organizations (manufacturers of capital goods) have found difficulties in marketing their products in emerging markets. They have worked with local users, manufacturers, and distributors to produce a feasible (meets user requirements) and viable (within cost and profit margin budgets) series of health care products. The more innovative among them consider "reverse innovation" or "frugal innovation" opportunities to re-engineer their product-services to meet specific 'local' requirements as a sound strategy for growth. General Electric and Panasonic have been notably successful in this approach. "Commoditization"; Dell Computers commenced selling laptop computers through retail outlets such as Wal-Mart in the USA in 2010 marking a significant change in distribution strategy. The product offers characteristics that allow basic applications to be used; they have in fact become commodity products that meet and offer limited user expectations and are made available in convenient locations patronized by the target market. De-commoditization examples include mineral water pack-size differentiation to meet convenience and location availability, FMCG internet shopping and home delivery. [10].

\section{Concluding Comments}

This paper has explored recent additions (and proposals) to the product-life-cycle concept that has conceptual and practical interests to academics and practitioners. Earlier the changing nature of the product-service life cycle was discussed; one of the topics raised in the discussion was that of commoditization and its implications. 
Developing an understanding of the impact on current customers' business models of downstream changes in their expectations (and their customers' expectations) and the implications these may have on the supplier organisation's strategic and operational decisions: do they require short-term adjustments to the organisation's positioning in Operational Business Areas or do they present longer-term concerns for strategic positioning in the Strategic Business Area? An ongoing examination of the changes in cost structures (fixed and variable) and the implications these have on customer expectations, network partners, and stakeholder partners. Clearly there is a changing role for an integrated and coordinated role of; marketing, research, design and development, operations and finance and with partner organisations if the ProductService-Life-Cycle based business model is to be effective.

\section{References}

1. Kotler, P.: Marketing Management, 8th edn. Prentice Hall, New York (1994)

2. Doyle, P.: Marketing Management and Strategy. Prentice Hall, London (1994)

3. Ansoff, H.I.: Implanting Strategic Management. Prentice Hall, New York (1984)

4. Johnson, M.: Seizing the White Space. Harvard Business Press, Boston (2010)

5. Capgemini: Service as a Strategy, http://www. capgemini.com/m/en/tl/ t1_Service_as_a_Strategy.pdf

6. Capgemini: Making the Shift to Service Management, http: //www. capgemini.com/insights-and-resources / by-publication/making-the-shift-to-service-management/

7. Katz, R.: What's Killing Japanese Electronics? Wall Street Journal (March 23, 2012)

8. Vargo, S., Lusch, R.: Evolving to a new dominant logic for marketing. J. of Marketing 68, $1-17(2004)$

9. Slywotzky, A.J., Morrison, D.J.: The Profit Zone. Wiley, New York (1997)

10. Schumpeter: Frugal ideas are spreading from East to West. Economist (May 24, 2012) 